\title{
Does an all-sulphur analogue of heptamolybdate exist?
}

\author{
BIKSHANDARKOIL R SRINIVASAN \\ Department of Chemistry, Goa University PO, Goa 403 206, India \\ e-mail: srini@unigoa.ac.in
}

MS received 27 November 2003; revised 1 June 2004

\begin{abstract}
The complexes $\left[\mathrm{MoX}_{4}\right]^{2-}(\mathrm{M}=\mathrm{Mo} ; \mathrm{X}=\mathrm{O}$ or $\mathrm{S})$ exist as the monomeric tetrahedral species in aqueous alkaline solutions. Acidification of tetraoxomolybdate results in the condensation of the tetrahedral units via a series of polyoxomolybdates leading to the ultimate formation of the trioxide $\mathrm{MoO}_{3}$. Heptamolybdate $\left[\mathrm{Mo}_{7} \mathrm{O}_{24}\right]^{6-}$ is the first major polyanion of the acidification reaction. In contrast, acidification of tetrathiomolybdates leads to the formation of amorphous molybdenum trisulphide via a dinuclear $\mathrm{Mo}(\mathrm{V})$ complex. The formation of the dinuclear $\mathrm{Mo}(\mathrm{V})$ complex precludes the formation of any higher nuclearity Mo(VI)-S complexes in aqueous solution. Thus it is shown that the all-sulphur analogue of heptamolybdate $\left[\mathrm{Mo}_{7} \mathrm{~S}_{24}\right]^{6-}$ does not exist in alkaline medium and also cannot be isolated from aqueous acidic medium.
\end{abstract}

Keywords. Tetraoxomolybdate; heptamolybdate; tetrathiomolybdate; dinuclear; all-sulphur analogue.

\section{Introduction}

Group VI metals Mo and W exhibit a wide variety of stereochemistries as well as a variety of oxidation states. Their chemistry has been described as the most complex of those of the transition elements by Cotton. ${ }^{1}$ The emerging chemistry of polyoxometalates $^{2}$ which exhibit fascinating structures like giant wheels, ${ }^{3,4}$ giant wheels linked to chains, ${ }^{5}$ giant molecular spheres of the Keplerate type ${ }^{6,7}$ giant molecular baskets ${ }^{8}$ etc. is a testimony to the complex chemistry of Mo. In recent years, several polyoxomolybdates have been structurally characterised, representative examples being $\mathrm{Na}_{7}\left[\mathrm{Mo}_{7} \mathrm{O}_{24}\right] \mathrm{OH}$. $21 \mathrm{H}_{2} \mathrm{O},{ }^{9}\left(\text { dapH }_{2}\right)_{2}\left[\mathrm{Mo}_{8} \mathrm{O}_{26}\right]^{10}\left(\right.$ dapH $_{2}=1$,3-propanediammonium), $\left(\operatorname{dienH}_{3}\right)_{2}\left[\mathrm{Mo}_{9} \mathrm{O}_{30}\right]^{10} \quad\left(\right.$ dienH $_{3}=$ diethylenetriammonium), $\mathrm{K}_{8}\left[\mathrm{Mo}_{36} \mathrm{O}_{112}\left(\mathrm{H}_{2} \mathrm{O}\right)_{16}\right]^{11}$ and $\left[\mathrm{La}\left(\mathrm{H}_{2} \mathrm{O}\right)_{7} \mathrm{Al}(\mathrm{OH})_{6} \mathrm{Mo}_{6} \mathrm{O}_{18}\right] .4 \mathrm{H}_{2} \mathrm{O} .{ }^{12}$ Interestingly all these complexes have been isolated from acidic media. The formation of the different oxomolybdates is $\mathrm{pH}$ dependent and can be summarised as below,

$$
\begin{aligned}
{\left[\mathrm{MoO}_{4}\right]^{2-} } & \rightarrow\left[\mathrm{Mo}_{7} \mathrm{O}_{24}\right]^{6-} \\
& \rightarrow\left[\mathrm{Mo}_{8} \mathrm{O}_{26}\right]^{4-} \rightarrow \ldots \mathrm{MoO}_{3} .
\end{aligned}
$$

Acidification of an aqueous alkaline solution of $\left[\mathrm{MoO}_{4}\right]^{2-}$ results in the condensation of the tetrahedral
$\mathrm{MoO}_{4}$ units giving rise to polynuclear oxomolybdates. The ultimate product of the acidification is $\mathrm{MoO}_{3}$, while the first product of the acidification reaction, at a $\mathrm{pH}$ below about 6 , is the heptamolybdate $^{13}\left[\mathrm{Mo}_{7} \mathrm{O}_{24}\right]^{6-}$ which is made up of exclusively $\mathrm{MoO}_{6}$ octahedra in which all the metals retain the +6 state. The heptamolybdate has been shown to be the predominant intermediate ${ }^{14}$ and has been isolated with a variety of cations from acidic media. From a structural point of view $\left[\mathrm{Mo}_{7} \mathrm{O}_{24}\right]^{6-}$ is very interesting in view of its flexibility to exist in different structural environments, with different counter cations. ${ }^{15-22}$ Anions with 8 and 36 Mo atoms are also formed before the increasing acidity suffices to precipitate the hydrous oxide. Conversely, when $\mathrm{MoO}_{3}$ is dissolved in aqueous alkali or an organic amine, the resulting solution contains tetrahedral $\left[\mathrm{MoO}_{4}\right]^{2-}$ ions and simple or normal molybdates can be crystallized from this solution. ${ }^{23,24}$

Mo-S compounds behave like the oxometalates, but with minor differences. Thus the tetrahedral ammonium tetrathiomolybdate $\left(\mathrm{NH}_{4}\right)_{2}\left[\mathrm{MoS}_{4}\right] \mathbf{1}$ complex is prepared ${ }^{25}$ by reacting an ammoniacal solution of heptamolybdate with $\mathrm{H}_{2} \mathrm{~S}$, a reaction first investigated by Berzelius. ${ }^{26} \mathrm{In}$ addition to its routine use as a starting material for the synthesis of a variety of polythiomolybdates ${ }^{27,28}$ and S-bridged multimetallic complexes, ${ }^{29-32}$ complex $\mathbf{1}$ has been shown to be a useful precursor for the preparation of amor- 
phous $\mathrm{MoS}_{3}{ }^{33}$ and $\mathrm{MoS}_{2}$ nanotubes. ${ }^{34}$ Further 1 has been introduced as an useful S-transfer reagent for the facile synthesis of organic disulphides in aqueous media. ${ }^{35}$ The related complex benzyltriethylammonium tetrathiomolybdate $\left[\left(\mathrm{PhCH}_{2}\right) \mathrm{N}\left(\mathrm{C}_{2} \mathrm{H}_{5}\right)_{3}\right]_{2}\left[\mathrm{MoS}_{4}\right]$ that is soluble in organic solvents has been shown to be a versatile S-transfer reagent for the convenient synthesis of a variety of organo-sulphur compounds. ${ }^{36,37}$ Acidification of $\left[\mathrm{MoS}_{4}\right]^{2-}$ results in the formation of the insoluble $\mathrm{MoS}_{3}$ as the ultimate product. $^{33,38}$

Unlike the oxomolybdates, several of which can be isolated from acidic media, only two Mo-S complexes made up of the dinuclear $\left\{\mathrm{Mo}_{2}(\mu-\mathrm{S})_{2}(\mathrm{X})_{2}\right\}^{2+}$ $(\mathrm{X}=\mathrm{O}$ or $\mathrm{S})$ moiety, in which both Mo are reduced to +5 , have been isolated till date by the acidification of aqueous tetrathiomolybdate. ${ }^{39,40}$ The acidification reactions are further complicated in view of the induced electron-transfer reactions across the $\mathrm{Mo}-\mathrm{S}$ bond which is a characteristic feature of Mo-S chemistry. ${ }^{41-43}$ Like the heptamolybdate, it is likely that the hitherto unknown all-sulphur analogue of heptamolybdate can be an important link in the chain of events leading to the formation of $\mathrm{MoS}_{3}$. In this context, the reported synthesis of $\left(\mathrm{NH}_{4}\right)_{6}\left[\mathrm{Mo}_{7} \mathrm{~S}_{24}\right]$ $2^{44}$ and the corresponding organic ammonium complex $\left[\left(\mathrm{PhCH}_{2}\right) \mathrm{N}\left(\mathrm{C}_{2} \mathrm{H}_{5}\right)_{3}\right]_{2}\left[\mathrm{Mo}_{7} \mathrm{~S}_{24}\right]$ attracted our attention. The unusual aspect of this report is the isolation of the heptanuclear $\left[\mathrm{Mo}_{7} \mathrm{~S}_{24}\right]^{6-}$ complex from an alkaline medium under the Berzelius conditions. Hence we reinvestigated the earlier work by Kaushik and coworkers and reported ${ }^{45}$ that the complex $\left[\left(\mathrm{PhCH}_{2}\right) \mathrm{N}\right.$ $\left.\left(\mathrm{C}_{2} \mathrm{H}_{5}\right)_{3}\right]_{2}\left[\mathrm{Mo}_{7} \mathrm{~S}_{24}\right]$ is actually the well-documented S-transfer reagent $\left[\left(\mathrm{PhCH}_{2}\right) \mathrm{N}\left(\mathrm{C}_{2} \mathrm{H}_{5}\right)_{3}\right]_{2}\left[\mathrm{MoS}_{4}\right]$. The present report is focused on the synthesis of the elusive $\left[\mathrm{Mo}_{7} \mathrm{~S}_{24}\right]^{6-}$ complex as the corresponding oxo analogue can be easily synthesized. The results of these investigations are described in this paper.

\section{Experimental}

All the chemicals used in this study were of reagent grade and used as received. Doubly distilled water was used as the solvent. The complexes $\left(n-\mathrm{Bu}_{4} \mathrm{~N}\right)_{2}$ $\left[\mathrm{Mo}_{2} \mathrm{OS}_{7}\right]^{39}(n$-Bu $=n$-butyl $)$ and $\left[\mathrm{Ni}(\mathrm{en})_{3}\right] \mathrm{Cl}_{2} \cdot 2 \mathrm{H}_{2} \mathrm{O}^{46}$ were prepared by literature methods. IR spectra were recorded on a Shimadzu (model 8101A) FTIR spectrometer in the range $4000-400 \mathrm{~cm}^{-1}$. The samples for the infrared spectra were prepared as $\mathrm{KBr}$ diluted pellets in the solid state and the infrared signals were referenced to polystyrene bands. Electronic spectra were recorded in dilute ammonia using matched quartz cells on a Perkin-Elmer (Lambda 12) spectrophotometer. The $\mathrm{pH}$ measurements were made on a LabIndia $\mathrm{pH}$ meter. The ammonium content of compounds $\mathbf{1}$ and $\mathbf{2}$ were estimated as the insoluble ammonium tetraphenylborate. ${ }^{47}$

\subsection{Preparation of $\left(\mathrm{NH}_{4}\right)_{2}\left[\mathrm{MoS}_{4}\right] \mathbf{1}^{25}$}

Ammonium heptamolybdate ( $3 \mathrm{~g})$ was dissolved in water $(5 \mathrm{ml})$. Liquor ammonia $(13.5 \mathrm{ml}$, sp. gr. 0.91$)$ was added to obtain a clear solution $(\mathrm{pH}=12 \cdot 1)$. Into this solution, $\mathrm{H}_{2} \mathrm{~S}$ gas was passed and the temperature was maintained at $60^{\circ} \mathrm{C}$ throughout the reaction. After $30 \mathrm{~min}$ when crystals started appearing, gas passage was stopped. The $\mathrm{pH}$ of the reaction mixture at this stage was found to be $10 \cdot 51$. The reaction mixture was cooled at $0^{\circ} \mathrm{C}$. The crystals were isolated by filtration, washed well with isopropanol, followed by ether and dried in vacuo. Yield $4 \cdot 1 \mathrm{~g}$.

Anal. Found (Calcd) for $\left(\mathrm{NH}_{4}\right)_{2}\left[\mathrm{MoS}_{4}\right]:\left(\mathrm{NH}_{4}\right)$ 13.85 (13.87), Mo 36.70 (36.85) S 49.11 (49.28)\%. IR: $\left(v_{\text {(Mo-S) }}\right) 478 \mathrm{~cm}^{-1}$. UV-Vis (dil. $\left.\mathrm{NH}_{4} \mathrm{OH}\right): 469$, 317 and $242 \mathrm{~nm}$.

\subsection{Preparation of compound $\mathbf{2}^{44}$}

Ammonium heptamolybdate ( $3 \mathrm{~g})$ was dissolved in water $(5 \mathrm{ml})$ and liquor ammonia $(13.5 \mathrm{ml}$, sp. gr. $0.91)$ was added to obtain a clear solution $(\mathrm{pH}=$ $12 \cdot 1$ ). Into this solution $\mathrm{H}_{2} \mathrm{~S}$ gas was continuously passed for $5 \mathrm{~h}$ and the temperature was maintained at $60^{\circ} \mathrm{C}$ throughout the reaction. The $\mathrm{pH}$ of the reaction mixture at this stage was found to be 10.09. After $5 \mathrm{~h}$ of gas passing, the reaction mixture was cooled to $0^{\circ} \mathrm{C}$. The solid was isolated by filtration, washed well with isopropanol, followed by ether and dried in vacuo. Yield $4.3 \mathrm{~g}$. It is to be noted that after half an hour crystals of $\left(\mathrm{NH}_{4}\right)_{2}\left[\mathrm{MoS}_{4}\right]$ started appearing in the solution. These crystals tend to block the passage of $\mathrm{H}_{2} \mathrm{~S}$ gas. Hence it is desirable to use a wide-mouthed gas-passing tube or alternatively change the tube periodically.

Anal. Found (Calcd) for $\left(\mathrm{NH}_{4}\right)_{6}\left[\mathrm{Mo}_{7} \mathrm{~S}_{24}\right]:\left(\mathrm{NH}_{4}\right)$ 13.84 (6.98), Mo 36.70 (43.34) S 49.08 (49.68)\%. IR: $\left(\mathrm{v}_{\text {(Mo-S })}\right) 478 \mathrm{~cm}^{-1}$; UV-Vis (dil. $\left.\mathrm{NH}_{4} \mathrm{OH}\right): 469$, 317 and $242 \mathrm{~nm}$.

Note: The analytical data are not in agreement with the proposed formula $\left(\mathrm{NH}_{4}\right)_{6}\left[\mathrm{Mo}_{7} \mathrm{~S}_{24}\right]$ in ref. 44 but to $\left(\mathrm{NH}_{4}\right)_{2}\left[\mathrm{MoS}_{4}\right] \mathbf{1}$. 
2.3 Reactions of $\mathbf{1}$ and $\mathbf{2}$ with sodium tetraphenylborate

$\left(\mathrm{NH}_{4}\right)_{2}\left[\mathrm{MoS}_{4}\right] \mathbf{1}(130 \mathrm{mg})$ was dissolved in water $(10 \mathrm{ml})$. A solution of $(360 \mathrm{mg})$ of sodium tetraphenylborate $\left(\mathrm{NaBPh}_{4}\right)$ in water $(30 \mathrm{ml})$ was slowly added in drops into the solution of $\mathbf{1}$ under stirring. This resulted in the immediate precipitation of $\mathrm{NH}_{4}\left(\mathrm{BPh}_{4}\right)$. The reaction mixture was kept aside for $1 \mathrm{~h}$ and filtered. The white precipitate of $\mathrm{NH}_{4}\left(\mathrm{BPh}_{4}\right)$ was washed well with ice-cold water till the washings were colourless, and then dried in vacuum and weighed to get $340.5 \mathrm{mg}$ of precipitate. $\% \mathrm{NH}_{4}$ in $\mathbf{1}$ $13.85 \%$. In another experiment, the reaction of $130 \mathrm{mg}$ of compound 2 with $(360 \mathrm{mg})$ of $\left[\mathrm{NaBPh}_{4}\right]$ in water $(30 \mathrm{ml})$ under identical conditions as mentioned above resulted in the formation of $336.3 \mathrm{mg}$ of $\mathrm{NH}_{4}\left(\mathrm{BPh}_{4}\right) . \% \mathrm{NH}_{4}$ in $213 \cdot 84 \%$.

\subsection{Reactions of $\mathbf{1}$ and $\mathbf{2}$ with [Ni(en $\left.)_{3}\right] \mathrm{Cl}_{2} \cdot 2 \mathrm{H}_{2} \mathrm{O}$}

A solution of $\left(\mathrm{NH}_{4}\right)_{2}\left[\mathrm{MoS}_{4}\right] \mathbf{1}(260 \mathrm{mg})$ in water $(15 \mathrm{ml})$ was added in drops into an aqueous solution of $\left[\mathrm{Ni}(\mathrm{en})_{3}\right] \mathrm{Cl}_{2} \cdot 2 \mathrm{H}_{2} \mathrm{O}(370 \mathrm{mg}$ in $20 \mathrm{ml})$ under stirring. This resulted in the immediate precipitation of $\left[\mathrm{Ni}(\mathrm{en})_{3}\right]\left[\mathrm{MoS}_{4}\right]$. The reaction mixture was kept aside for $1 \mathrm{~h}$ and filtered. The orange-red precipitate of $\left[\mathrm{Ni}(\mathrm{en})_{3}\right]\left[\mathrm{MoS}_{4}\right]$ was washed well with ice-cold water till the washings were colourless, and then dried in vacuum and weighed to get $460 \mathrm{mg}$ of precipitate. $\% \mathrm{MoS}_{4}$ is $85 \cdot 38$. The use of $260 \mathrm{mg}$ of 2 instead of 1 under identical conditions as mentioned above resulted in the formation of $461 \mathrm{mg}$ of the orange precipitate of $\left[\mathrm{Ni}(\mathrm{en})_{3}\right]\left[\mathrm{MoS}_{4}\right] . \% \mathrm{MoS}_{4}$ is $85 \cdot 84$.

\subsection{Reaction of $\mathbf{1}$ with dilute $\mathrm{HCl}$}

$\left(\mathrm{NH}_{4}\right)_{2}\left[\mathrm{MoS}_{4}\right] \mathbf{1}(650 \mathrm{mg})$ was dissolved in water $(15 \mathrm{ml})$ and the $\mathrm{pH}$ of the red solution was found to be 7.99. Into this solution $0.6 \mathrm{ml}$ of $2 \mathrm{~N} \mathrm{HCl}$ was added under continuous stirring. The colour of the solution changed to dark red and the $\mathrm{pH}$ of the solution at this stage had decreased to $7 \cdot 11$. Addition of $\left[(n-\mathrm{Bu})_{4} \mathrm{~N}\right] \mathrm{Cl}(n-\mathrm{Bu}=$ butyl $)$ at this stage, afforded the dinuclear compound $\left[(n-\mathrm{Bu})_{4} \mathrm{~N}\right]_{2}\left[\mathrm{Mo}_{2} \mathrm{OS}_{7}\right]$ as reported previously. ${ }^{39}$ If no organic cation is added and acidification is continued, this results in the formation of an insoluble black compound $\mathrm{MoS}_{3}$ below $\mathrm{pH}=4$.

\subsection{Direct reaction of $\left[\mathrm{Mo}_{7} \mathrm{O}_{24}\right]^{6-}$ with $\mathrm{H}_{2} \mathrm{~S}$}

Ammonium heptamolybdate $(1 \mathrm{~g})$ was dissolved in water $(20 \mathrm{ml})$ and a rapid stream of $\mathrm{H}_{2} \mathrm{~S}$ gas was passed into this solution for $30 \mathrm{~min}$. The colour of the solution changed from colourless to dark red at the end of $30 \mathrm{~min}$. The dark red reaction mixture was left aside for crystallization. The electronic spectrum of the final reaction mixture was characteristic of complexes with a $\left\{\mathrm{Mo}_{2}(\mu-\mathrm{S})_{2}\right\}^{6+}$ core $^{39}$ indicating the reduction of $\mathrm{Mo}(\mathrm{VI})$ to $\mathrm{Mo}(\mathrm{V})$. An aqueous solution of $\left(n-\mathrm{Bu}_{4} \mathrm{~N}\right) \mathrm{Br}(2 \mathrm{~g}$ in $10 \mathrm{ml})$ was added into the reaction mixture under stirring, resulting in the formation of a dark red complex. Filtration of the reaction mixture followed by washing with 2-propanol and ether yielded $2 \cdot 1 \mathrm{~g}$ of the binuclear Mo(V) complex. The IR spectrum of the product with bands at $936\left(\mathrm{v}_{(\mathrm{Mo}-\mathrm{O})}\right), 516\left(\mathrm{v}_{(\mathrm{S}-\mathrm{S})}\right)$ and 469 $\left(\mathrm{v}_{(\mathrm{Mo}-\mathrm{S})}\right) \mathrm{cm}^{-1}$ matches well with that of the reported complex $\left(n-\mathrm{Bu}_{4} \mathrm{~N}\right)_{2}\left[\mathrm{Mo}_{2} \mathrm{OS}_{7}\right] .{ }^{39}$ In the absence of an added cation, no product could be isolated.

\section{Results and discussion}

\subsection{Relevance of medium $\mathrm{pH}$ for synthesis}

The $\mathrm{pH}$ values of aqueous solutions of the group VI tetraoxometalates and tetrathiometalates as well as that of heptamolybdate were determined and are collected in table 1 . The saturated solutions of all the tetraoxometallates are quite alkaline as evidenced by their $\mathrm{pH}$, excepting that of heptamolybdate which is acidic. When an excess aqueous ammonia is added to an acidic heptamolybdate solution the resulting $\mathrm{pH}(12 \cdot 1)$ is more alkaline than that of saturated mo-

Table 1. pH values of some aqueous oxo and thiometalate solutions.

\begin{tabular}{|c|c|c|c|}
\hline \multirow[b]{2}{*}{ Compound } & \multicolumn{3}{|c|}{$\mathrm{pH}$} \\
\hline & $0 \cdot 01 \mathrm{M}$ & $0 \cdot 1 \mathrm{M}$ & Saturated \\
\hline $\mathrm{K}_{2} \mathrm{CrO}_{4}$ & $8 \cdot 81$ & $9 \cdot 74$ & $10 \cdot 58$ \\
\hline $\mathrm{Na}_{2} \mathrm{MoO}_{4}$ & $6 \cdot 97$ & $8 \cdot 59$ & $9 \cdot 69$ \\
\hline $\mathrm{Na}_{2} \mathrm{WO}_{4}$ & $7 \cdot 34$ & $9 \cdot 83$ & $10 \cdot 26$ \\
\hline$\left(\mathrm{NH}_{4}\right)_{2}\left[\mathrm{MoS}_{4}\right] \mathbf{1}$ & $7 \cdot 81$ & $8 \cdot 0$ & $8 \cdot 95$ \\
\hline Compound 2 & $7 \cdot 83 *$ & $8 \cdot 0$ & $8 \cdot 90$ \\
\hline$\left(\mathrm{NH}_{4}\right)_{2}\left[\mathrm{WS}_{4}\right]$ & $6 \cdot 65$ & $7 \cdot 08$ & $7 \cdot 50$ \\
\hline$\left(\mathrm{NH}_{4}\right)_{6}\left[\mathrm{Mo}_{7} \mathrm{O}_{24}\right]$ & $5 \cdot 18$ & - & $5 \cdot 3$ \\
\hline
\end{tabular}

*This solution was prepared using $0.260 \mathrm{~g}$ of 2 in $100 \mathrm{ml}$ 
lybdate. Under this condition, only the tetrahedral $\left[\mathrm{MoO}_{4}\right]^{2-}$ species can exist in solution. ${ }^{1,24}$ After $\mathrm{H}_{2} \mathrm{~S}$ gas is passed into this solution for $30 \mathrm{~min}$ the $\mathrm{pH}$ $(10 \cdot 51)$ of the solution is slightly decreased but the solution is still more alkaline than that of saturated tetrathiomolybdate. The decrease in $\mathrm{pH}$ can be attributed to the formation of thiomolybdate and also to the presence of $\mathrm{H}_{2} \mathrm{~S}$, which is a weak acid in the reaction mixture. Cooling the reaction mixture and filtering affords ammonium tetrathiomolybdate $\mathbf{1}$ in high yields. The formation of $\left(\mathrm{NH}_{4}\right)_{2}\left[\mathrm{MoS}_{4}\right]$ under these conditions is well known from the days of Berzelius and is well documented in the literature. ${ }^{25}$ The reported synthesis of $\left[\mathrm{Mo}_{7} \mathrm{~S}_{24}\right]^{6-}$ essentially uses a similar reaction protocol. ${ }^{44}$ However, $\mathrm{H}_{2} \mathrm{~S}$ gas is passed into the ammoniacal heptamolybdate solution $(\mathrm{pH}=12 \cdot 1)$ for an extended period of $5 \mathrm{~h}$ instead of $30 \mathrm{~min}$ for $\mathbf{1}$. The $\mathrm{pH}$ of the reaction mixture after passing $\mathrm{H}_{2} \mathrm{~S}$ for $5 \mathrm{~h}$ was found to be 10.09 which is slightly less than that observed (10.51) for the synthesis of $\mathbf{1}$. This can be easily explained as in this case the reaction mixture is quite saturated with $\mathrm{H}_{2} \mathrm{~S}$ in view of the long reaction time. However, the final reaction mixture is still alkaline and in fact more alkaline than that of the saturated solution of 1. The $\mathrm{pH}$ data give the initial proof that the reaction mixtures in both cases are nearly identical and should give rise to the same products as further evidenced by analytical and spectral data (vide infra). For the formation of a heptanuclear Mo-S compound it is essential that $\mathrm{S}$ atoms are removed from the tetrahedral $\left[\mathrm{MoS}_{4}\right]^{2-}$ moiety in the form of $\mathrm{H}_{2} \mathrm{~S}$ as is done for heptamolybdate wherein the condensation of $\left[\mathrm{MoO}_{4}\right]^{2-}$ units are effected on acidification, by removing $\mathrm{O}$ in the form of $\mathrm{H}_{2} \mathrm{O}$. As the medium is strongly alkaline no such condensation can be effected. The reaction of compounds $\mathbf{1}$ and $\mathbf{2}$ with benzyltriethylammonium chloride results in cation exchange and the corresponding water insoluble but organic soluble organic ammonium thiomolybdates can be obtained. The role of the bulky organic cation is essentially to enhance the solubility in organic solvents.

\subsection{Analytical and spectral studies}

The mononuclear Mo-S compound $\mathbf{1}$ and the heptanuclear compound $\mathbf{2}$ can be readily distinguished in terms of the analytical data especially the $\% \mathrm{NH}_{4}$. The ammonium content of both $\mathbf{1}$ and $\mathbf{2}$ were estimated gravimetrically as ammonium tetraphenylbo- rate by using the same amount of $\mathbf{1}$ or $\mathbf{2}$ for analysis under identical conditions. The ammonium content of $2(13.84)$ corresponds to $\left(\mathrm{NH}_{4}\right)_{2}\left[\mathrm{MoS}_{4}\right] \mathbf{1}$ (expected $13.87 \%$ ) and not to a heptanuclear formulation 2 which requires an ammonium percentage of 6.98. This observation clearly indicates that not only are compounds $\mathbf{1}$ and $\mathbf{2}$ the same but also not even a trace of heptanuclear complex is formed under the reaction conditions. The identical nature of $\mathbf{1}$ and $\mathbf{2}$ can be further shown by the analysis of their thiomolybdate content as $\left[\mathrm{Ni}(\mathrm{en})_{3}\right]\left[\mathrm{MoS}_{4}\right]$. In a recent paper, it has been reported that the insoluble complex $\left[\mathrm{Ni}(\mathrm{en})_{3}\right]\left[\mathrm{MoS}_{4}\right]$ can be obtained in excellent yields even under solvothermal conditions. ${ }^{48}$ This suggested to us that the insoluble nature of the [Ni(en $\left.)_{3}\right]\left[\mathrm{MoS}_{4}\right]$ complex can be used as a convenient method for determining the thiomolybdate content. ${ }^{49}$ Thus the reaction of complex $\mathbf{1}$ or $\mathbf{2}$ with $\left[\mathrm{Ni}(\mathrm{en})_{3}\right]^{2+}$ under aqueous conditions results in the formation of the highly insoluble complex $\left[\mathrm{Ni}(\mathrm{en})_{3}\right]$ $\left[\mathrm{MoS}_{4}\right]$ in quantitative yields. This reaction works equally well for water insoluble complexes like $\left[\left(\mathrm{PhCH}_{2}\right) \mathrm{N}\left(\mathrm{C}_{2} \mathrm{H}_{5}\right)_{3}\right]_{2}\left[\mathrm{MoS}_{4}\right]$, indicating the generality of this method. In this case, the thiomolybdate is dissolved in $\mathrm{CH}_{3} \mathrm{CN}$ and into this the $\mathrm{Ni}(\mathrm{II})$ complex is added resulting in the formation of $\left[\mathrm{Ni}(\mathrm{en})_{3}\right]$ $\left[\mathrm{MoS}_{4}\right] .{ }^{49}$ The infrared spectra of thiomolybdate complexes exhibit characteristic signatures for the Mo-S vibrations. The IR as well as the UV-Vis spectra of both the complexes are identical indicating that complexes $\mathbf{1}$ and $\mathbf{2}$ are one and the same. The triply degenerate asymmetric Mo-S stretching vibration is observed at $478 \mathrm{~cm}^{-1}$ in both complexes and this value is in excellent agreement with the reported value for $\left(\mathrm{NH}_{4}\right)_{2}\left[\mathrm{MoS}_{4}\right] \mathbf{1}^{25}$ The UV-Vis spectra of $\mathbf{1}$ and $\mathbf{2}$ exhibit characteristic charge transfer bands of the $\left[\mathrm{MoS}_{4}\right]^{2-}$ moiety as reportted. ${ }^{25,28}$ The identical nature of both the spectra indicates that the chromophore present in $\mathbf{1}$ and $\mathbf{2}$ is one and the same. Based on the $\mathrm{pH}$ studies, analytical, and spectral data mentioned above, the formation of the heptanuclear $\left[\mathrm{Mo}_{7} \mathrm{~S}_{24}\right]^{6-}$ complex under alkaline conditions can be ruled out. It can be further stated that passing $\mathrm{H}_{2} \mathrm{~S}$ gas into an alkaline molybdate solution for an extended period does not result in the formation of any new Mo-S product other than the well known $\left[\mathrm{MoS}_{4}\right]^{2-}$. This result is in accordance with the synthesis in alkaline media, as well as the structural characterization of several organic ammonium tetrathiomolybdate complexes. ${ }^{50-53}$ The earlier reported ${ }^{44}$ synthesis of $\left(\mathrm{NH}_{4}\right)_{2}\left[\mathrm{Mo}_{7} \mathrm{~S}_{24}\right]$ is in effect a 
cumbersome method for the preparation of $\left(\mathrm{NH}_{4}\right)_{2}$ $\left[\mathrm{MoS}_{4}\right]$.

\subsection{Comparative chemistry of heptamolybdate and its all-sulphur analogue}

The above mentioned discussions clearly indicate that no heptanuclear Mo-S complex can be assembled in an alkaline medium. If the earlier reported complex is not the $\left[\mathrm{Mo}_{7} \mathrm{~S}_{24}\right]^{6-}$ complex, it is pertinent to know how such a complex can be synthesised at all. The comparative chemistry of polyoxo and polythio molybdates can be useful to derive a suitable answer to the problem of the synthesis of the elusive $\left[\mathrm{Mo}_{7} \mathrm{~S}_{24}\right]^{6-}$ complex. The known chemistry of oxomolybdates as well as thiomoybdates describes several polynuclear species. However, both the chemistries differ considerably. For example, complexes like $\left[\mathrm{Mo}_{2} \mathrm{~S}_{12}\right]^{2-},\left[\mathrm{Mo}_{3} \mathrm{~S}_{9}\right]^{2-}\left[\mathrm{Mo}_{3} \mathrm{~S}_{13}\right]^{2-}$ have no corresponding oxo analogues. ${ }^{27,28,54}$ An important aspect of the Mo-S chemistry is the induced electron transfer across the Mo-S bond. Several polyoxomolybdates have been isolated from aqueous medium by acidification of the tetrahedral $\left[\mathrm{MoO}_{4}\right]^{2-}$. In contrast, many of the known polythiomolybdates have been synthesised from non-aqueous media.

A primary requirement for the $\left[\mathrm{Mo}_{7} \mathrm{~S}_{24}\right]^{6-}$ complex is that all the Mo atoms be in +6 oxidation state. Further all the $\mathrm{S}$ ligands bound to Mo(VI) should be $\mathrm{S}^{2-}$ which can be either terminal or bridging to achieve charge balance. The presence of $\left(\mathrm{S}_{2}\right)^{2-}$ or $\left(\mathrm{S}_{4}\right)^{2-}$ type of ligands can be conveniently ruled out based on charge considerations. A survey of the known polynuclear thiomolybdates ${ }^{27,28}$ indicates certain interesting features. Most of these complexes are synthesised under non-aqueous conditions. Most of the polythiometalates are anionic complexes isolated as organic salts by employing $\left(\mathrm{NEt}_{4}\right)^{+}$or $\left(\mathrm{PPh}_{4}\right)^{+}$counter cations, the only exceptions being the $\left[\mathrm{Mo}_{2} \mathrm{~S}_{12}\right]^{2-}$ and $\left[\mathrm{Mo}_{3} \mathrm{~S}_{13}\right]^{2-}$ complexes which are known as the ammonium salts. In almost all these complexes, at least one Mo is in a lower oxidation level namely +5 or even +4 as in $\left[\mathrm{Mo}_{3} \mathrm{~S}_{13}\right]^{2-}{ }^{23}$ In addition to $\mathrm{S}^{2-},\left(\mathrm{S}_{2}\right)^{2-}$ and $\left(\mathrm{S}_{4}\right)^{2-}$ type of ligands are also encountered in many of the polynuclear $\mathrm{Mo}-\mathrm{S}$ complexes. The complexes $\left[\mathrm{Mo}_{2} \mathrm{~S}_{11}\right]^{2-}$ and $\left[\mathrm{Mo}_{2} \mathrm{O}_{2} \mathrm{~S}_{9}\right]^{2-}$ are exceptions as in these dinuclear complexes both the Mo atoms retain their +6 state. A rational synthesis which employs $\left(\mathrm{PPh}_{4}\right)_{2}\left[\mathrm{MoS}_{4}\right]$ in $\mathrm{CH}_{3} \mathrm{CN}, \mathrm{S}$ and acetic acid has been reported ${ }^{55}$ for the synthesis of $\left[\mathrm{Mo}_{2} \mathrm{~S}_{11}\right]^{2-}$. In view of the stability of the tetrahedral $\left[\mathrm{MoS}_{4}\right]^{2-}$ core in alkaline media and the accessibility of dinuclear Mo-S complexes by acidification method, it appeared appropriate to investigate the acidification reactions of $\left[\mathrm{MoS}_{4}\right]^{2-}$ as a possible route for the synthesis of $\left[\mathrm{Mo}_{7} \mathrm{~S}_{24}\right]^{6-}$. It is to be noted that heptamolybdate can be readily crystallized from an aqueous ammonium molybdate solution by acidification. ${ }^{15-22}$ Further heptamolybdate exhibits the same structure in solution as in the solid state. Accordingly the reaction of aqueous $\left[\mathrm{MoS}_{4}\right]^{2-}$ was investigated with acid.

When an aqueous solution of $\left(\mathrm{NH}_{4}\right)_{2}\left[\mathrm{MoS}_{4}\right]$ is acidified with $\mathrm{HCl}$ and the $\mathrm{pH}$ is reduced to around 7 , colour change occurs accompanied by a change in the visible spectrum. At this stage, addition of tetrabutylammonium halide results in the formation of the known unsymmetrical dinuclear complex $\left[\mathrm{Mo}_{2} \mathrm{OS}_{7}\right]^{2-}$ in which both the Mo atoms are reduced to +5 . The formation of the dinuclear complex has been spectroscopically monitored by the visible spectrum and further confirmed based on the IR spectrum of the isolated compound. In the absence of an organic cation, no Mo-S complex can be isolated. Further acidification without adding any organic cation results in the formation of the insoluble black $\mathrm{MoS}_{3}$, which exhibits a featureless infrared spectrum. All our efforts to isolate a trinuclear or polynuclear Mo-S complexes by the acidification of $\left(\mathrm{NH}_{4}\right)_{2}\left[\mathrm{MoS}_{4}\right]$ were not fruitful. The only product in all these reactions was the amorphous $\mathrm{MoS}_{3}$. It is pertinent to note that the reported yield of the dinuclear $\mathrm{Mo}(\mathrm{V})$ complex is about $60 \%$ and even in this case substantial amounts of $\mathrm{MoS}_{3}$ are obtained as by-product. The non-accessibility of polynuclear Mo-S complexes can then be attributed either to their hydrolytic instability or to the facile formation of $\mathrm{MoS}_{3}$ or both. It is interesting to note that controlled acidification using 0.5 moles of $\mathrm{H}^{+}$per mole of $\left[\mathrm{MoS}_{4}\right]^{2-}$ leads to a predominantly dinuclear $\mathrm{Mo}(\mathrm{V})$ product while addition of two moles (excess) of acid results in the formation of the Mo(VI) complex $\mathrm{MoS}_{3}$. The formation of the dinuclear complex has been represented by Pope ${ }^{39}$ as follows:

$$
\begin{aligned}
2\left[\mathrm{MoS}_{4}\right]^{2-}+1 / 2 \mathrm{Q}+ & \mathrm{H}_{3} \mathrm{O}^{+} \rightarrow \\
& {\left[\mathrm{Mo}_{2} \mathrm{OS}_{7}\right]^{2-}+\mathrm{H}_{2} \mathrm{~S}+\mathrm{OH}^{-}, }
\end{aligned}
$$

wherein molecular $\mathrm{O}_{2}$ functions like an external oxidant to induce electron transfer across $\mathrm{Mo}^{\mathrm{VI}}-\mathrm{S}$ bond. The formation of the trisulphide can be represented as shown below. 


$$
\left[\mathrm{MoS}_{4}\right]^{2-}+2 \mathrm{H}^{+} \rightarrow \mathrm{MoS}_{3}+\mathrm{H}_{2} \mathrm{~S} .
$$

In their report on the aqueous synthesis of $\mathrm{MoS}_{3}$ Wang et $a l^{33}$ have shown that the $\mathrm{MoS}_{3}$ formed by the reaction of 1 with excess of dilute $\mathrm{H}_{2} \mathrm{SO}_{4}$ actually contains trace amounts of $\mathrm{MoS}_{2}$ as evidenced by powder diffraction, indicating the complex nature of the acidification reaction. While the individual formation of $\left[\mathrm{Mo}_{2} \mathrm{OS}_{7}\right]^{2-}$ or $\mathrm{MoS}_{3}$ can be rationalized by (2) or (3), it is still not clear as to how the initially formed $\mathrm{Mo}(\mathrm{V})$ dimer $((2))$ is reoxidised to $\mathrm{Mo}(\mathrm{VI})$ in $\mathrm{MoS}_{3}$. Further studies are essential to unravel the nature and characteristics of other transient intermediates before $\mathrm{MoS}_{3}$ is formed. The process of acidification of tetrathiomolybdate can be summarized as shown below.

$$
\begin{aligned}
{\left[\mathrm{MoS}_{4}\right]^{2-} \stackrel{\mathrm{H}^{+}}{\longrightarrow}\left[\left(\mathrm{S}_{2}\right)(\mathrm{S}) \mathrm{Mo}(\mu-\mathrm{S})_{2} \mathrm{Mo}(\mathrm{O})\left(\mathrm{S}_{2}\right)\right]^{2-} } \\
\stackrel{\mathrm{H}^{+}}{\longrightarrow} \ldots \mathrm{MoS}_{3} .
\end{aligned}
$$

As the acidification reaction did not lead to the assembling of the desired heptanuclear product but led instead to a reduced dimeric product, another method was investigated for the preparation of $\left[\mathrm{Mo}_{7} \mathrm{~S}_{24}\right]^{6-}$ complex. This method was modelled based on the synthesis of $\left[\mathrm{MoS}_{4}\right]^{2-}$ wherein the reaction of $\left[\mathrm{MoO}_{4}\right]^{2-}$ with $\mathrm{H}_{2} \mathrm{~S}$ results in the displacement of the oxo ligands by $\mathrm{S}^{2-}$, leading to the formation of the corresponding tetrathio analogue. Thus the reaction of $\left[\mathrm{Mo}_{7} \mathrm{O}_{24}\right]^{6-}$ a pre-assembled heptanuclear core was investigated by passing $\mathrm{H}_{2} \mathrm{~S}$ with a view to displacing the $\mathrm{O}^{2-}$ by $\mathrm{S}^{2-}$ leading to $\left[\mathrm{Mo}_{7} \mathrm{~S}_{24}\right]^{6-}$. Passing of $\mathrm{H}_{2} \mathrm{~S}$ directly into an aqueous solution of ammonium heptamolybdate $(\mathrm{pH}=5 \cdot 5)$ resulted in the formation of a dark red reaction mixture $(\mathrm{pH}=7 \cdot 1)$. The reason for the increase in $\mathrm{pH}$ is not very clear. The optical spectrum of the reaction mixture at this stage was very characteristic of the complexes containing the dinuclear $\left\{\mathrm{Mo}_{2} \mathrm{~S}_{4}\right\}^{2+}$ core indicating that ligand displacement accompanied with reduction is the favoured process. The non-accessibility of any polynuclear $\mathrm{Mo}(\mathrm{VI})-\mathrm{S}$ complexes in this reaction clearly indicates that addition of S-donor ligands on to the heptanuclear core leads to its collapse resulting in the formation of a dinuclear $\mathrm{Mo}(\mathrm{V})$ product. The addition of an organic cation like $\left[(n-\mathrm{Bu})_{4} \mathrm{~N}\right] \mathrm{Br}$ into the reaction mixture afforded the asymmetrical oxo, sulphido $\mathrm{Mo}(\mathrm{V})$ dimer which was identified by its characteristic IR spectrum. In the absence of any added cation the reaction mixture slowly decomposed to $\mathrm{MoS}_{3}$ over several days, while acidification at this stage resulted in the formation of black $\mathrm{MoS}_{3}$. The formation of the dinuclear $\mathrm{Mo}(\mathrm{V})$ complex is the key factor that precludes the formation of any higher nuclearity Mo-S complexes.

\subsection{Structural considerations}

Formation of the dinuclear $\mathrm{Mo}(\mathrm{V})$ complex under the investigated reaction conditions can be explained based on the known bond distances of Mo-S complexes. Table 2 lists the reported bond lengths of some oxo and thiomolybdates. The mononuclear tetrahedral $\left[\mathrm{MoX}_{4}\right]^{2-}(\mathrm{X}=\mathrm{O}$ or $\mathrm{S})$ complexes exhibit four terminal Mo-O or Mo-S distances at 1.795 and $2 \cdot 177 \AA$ respectively. The terminal Mo-O bond distances observed in the $\left[\mathrm{Mo}_{7} \mathrm{O}_{24}\right]^{6-}$ complex are shorter at $1.72 \AA$ than those observed in $\left[\mathrm{MoO}_{4}\right]^{2-}$. Assuming that $\left[\mathrm{Mo}_{7} \mathrm{~S}_{24}\right]^{6-}$ is isomorphous with its oxo analogue, namely heptamolybdate, it is expected that the structure of the all-sulphur analogue of heptamolybdate should support a total of $32 \mathrm{Mo}(\mathrm{VI})-\mathrm{S}$ bonds. Of these, the twelve terminal Mo-S bond lengths should be shorter than the Mo-S distances of $2 \cdot 177 \AA$ normally observed in $\left[\mathrm{MoS}_{4}\right]^{2-}$. Interestingly the expected shorter bond distances are observed in several $\mathrm{Mo}(\mathrm{V})-\mathrm{S}$ complexes (table 2). For the dinuclear complexes containing the $\left\{\mathrm{Mo}_{2} \mathrm{~S}_{4}\right\}^{2+}$ core only the terminal $\mathrm{Mo}(\mathrm{V})-\mathrm{S}$ lengths are shown and these distances range from $2 \cdot 092$ to $2 \cdot 129 \AA$. It is pertinent to note that these distances do not vary much even when the other ligands around Mo are changed. The observation of shorter Mo-S bonds in the dinuclear $\mathrm{Mo}(\mathrm{V})$ complexes is indicative of the fact that a closer approach of $S$ to Mo results in electron transfer and consequently reduction of $\mathrm{Mo}(\mathrm{VI})$ to $\mathrm{Mo}(\mathrm{V})$. This feature is not surprising because electron transfer across the Mo-S bond is a well known phenomenon ${ }^{41-43}$ and indeed the formation of several Mo-S compounds, especially the dinuclear complexes like $\left[\mathrm{Mo}_{2} \mathrm{~S}_{3} \mathrm{O}\left(\mathrm{S}_{2}\right)_{2}\right]^{2-},\left[\mathrm{Mo}_{2} \mathrm{~S}_{4}\right.$ $\left.\left(\mathrm{S}_{2}\right)_{2}\right]^{2-},\left[\mathrm{Mo}_{2} \mathrm{~S}_{2} \mathrm{O}_{2}\left(\mathrm{~S}_{2}\right)_{2}\right]^{2-}$, has been explained based on such electron transfer. ${ }^{39,41,42}$ While the formation of the $\left[\mathrm{Mo}_{2} \mathrm{OS}_{7}\right]^{2-}$ complex can be rationalized in terms of the shorter Mo-S bond distances, the same argument can also be extended to explain the nonaccessibility of $\left[\mathrm{Mo}_{7} \mathrm{~S}_{24}\right]^{6-}$. The structural requirements of $\left[\mathrm{Mo}_{7} \mathrm{~S}_{24}\right]^{6-}$ demands twelve Mo-S bonds at shorter distances than in $\left[\mathrm{MoS}_{4}\right]^{2-}$, which cannot be met, as the closer approach of $\mathrm{S}$ to Mo leads to electron transfer resulting in the collapse of the heptanuclear Mo(VI) structure. This argument gains 
Table 2. Selected bond distances $d$, number of Mo-S (term) of distances $n$, of a few oxo and thiomolybdates ${ }^{\mathrm{a}}$.

\begin{tabular}{|c|c|c|c|c|}
\hline Complex & Bond & $d($ in $\AA)$ & $n$ & Ref. \\
\hline$\left[\mathrm{MoO}_{4}\right]^{2-}$ & $\mathrm{Mo}(\mathrm{VI})-\mathrm{O}($ term $)$ & 1.795 & 4 & 56 \\
\hline \multirow[t]{3}{*}[\mathrm{Mo}_{7}\mathrm{O}_{24}]{$^{6-}$} & $\mathrm{Mo}(\mathrm{VI})-\mathrm{O}($ term $)$ & $1 \cdot 72$ & 12 & 17 \\
\hline & $\mathrm{Mo}(\mathrm{VI})-\mathrm{O}(\mathrm{br})$ & 1.93 & 14 & \\
\hline & $\mathrm{Mo}(\mathrm{VI})-\mathrm{O}(\mathrm{br})$ & $2 \cdot 27$ & 6 & \\
\hline$\left[\mathrm{MoS}_{4}\right]^{2-}$ & $\mathrm{Mo}(\mathrm{VI})-\mathrm{S}($ term $)$ & $2 \cdot 177$ & 4 & 57 \\
\hline \multirow[t]{3}{*}[\mathrm{Mo}_{7}\mathrm{S}_{24}]{$^{6-}$} & $\mathrm{Mo}(\mathrm{VI})-\mathrm{S}($ term $)$ & - & 12 & - \\
\hline & $\mathrm{Mo}(\mathrm{VI})-\mathrm{S}(\mathrm{br})$ & - & 14 & \\
\hline & $\mathrm{Mo}(\mathrm{VI})-\mathrm{S}$ (br) & - & 6 & \\
\hline$\left[\mathrm{Mo}_{2} \mathrm{~S}_{4}\left(\mathrm{~S}_{2}\right)_{2}\right]^{2-}$ & $\mathrm{Mo}(\mathrm{V})-\mathrm{S}($ term $)$ & $2 \cdot 118$ & 2 & 41 \\
\hline$\left[\mathrm{Mo}_{2} \mathrm{~S}_{3} \mathrm{O}\left(\mathrm{S}_{2}\right)_{2}\right]^{2-}$ & $\mathrm{Mo}(\mathrm{V})-\mathrm{S}($ term $)$ & $2 \cdot 11$ & 1 & 39 \\
\hline$\left[\mathrm{Mo}_{2} \mathrm{~S}_{4}\left(\mathrm{~S}_{2}\right)\left(\mathrm{S}_{4}\right)\right]^{2-}$ & $\mathrm{Mo}(\mathrm{V})-\mathrm{S}$ (term) & $2 \cdot 110$ & 2 & 58 \\
\hline$\left[\mathrm{Mo}_{2} \mathrm{~S}_{4}\left(\mathrm{~S}_{4}\right)\left(\mathrm{S}_{4}\right)\right]^{2-}$ & $\mathrm{Mo}(\mathrm{V})-\mathrm{S}($ term $)$ & $2 \cdot 118$ & 2 & 59 \\
\hline$\left[\mathrm{Mo}_{2} \mathrm{~S}_{4}(\mathrm{edt})_{2}\right]^{2-}$ & $\mathrm{Mo}(\mathrm{V})-\mathrm{S}($ term $)$ & $2 \cdot 100$ & 2 & 60 \\
\hline$\left[\mathrm{Mo}_{2} \mathrm{~S}_{4}(\mathrm{edt})_{2}\right]^{2-\#}$ & $\mathrm{Mo}(\mathrm{V})-\mathrm{S}$ (term) & $2 \cdot 129$ & 2 & 60 \\
\hline$\left[\mathrm{Mo}_{2} \mathrm{~S}_{4}(\mathrm{Et}-\mathrm{dtc})_{2}\right]$ & $\operatorname{Mo}(\mathrm{V})-\mathrm{S}$ (term) & $2 \cdot 092$ & 2 & 61 \\
\hline$\left[\mathrm{Mo}_{2} \mathrm{~S}_{4}\left(\mathrm{CS}_{4}\right)_{2}\right]^{2-}$ & $\mathrm{Mo}(\mathrm{V})-\mathrm{S}($ term $)$ & $2 \cdot 100$ & 2 & 62 \\
\hline$\left[\mathrm{Mo}_{2} \mathrm{~S}_{4}\left(\mathrm{CS}_{3}\right)_{2}\right]^{2-}$ & $\mathrm{Mo}(\mathrm{V})-\mathrm{S}$ (term) & $2 \cdot 108$ & 2 & 62 \\
\hline
\end{tabular}

${ }^{a}$ Abbreviations: term $=$ terminal; br $=$ bridging; $\left\{\mathrm{Mo}_{2} \mathrm{~S}_{4}\right\}=\left[(\mathrm{S}) \mathrm{Mo}(\mu-\mathrm{S})_{2} \mathrm{Mo}\right.$ $(\mathrm{S})]^{2+}$; edt $=$ ethanedithiolate; ${ }^{\#}$ anti isomer; Et-dtc $=\mathrm{N}, \mathrm{N}^{\prime}$-diethyldithiocarbamate

credence based on the results of the direct reaction of $\mathrm{H}_{2} \mathrm{~S}$ with $\left[\mathrm{Mo}_{7} \mathrm{O}_{24}\right]^{6-}$ (vide supra). To the best of my knowledge there is no report of a $\mathrm{Mo}(\mathrm{VI})-\mathrm{S}$ terminal bond in any complex at around $2.11 \AA$. In contrast, the closer approach of the oxide ligands in $\left[\mathrm{Mo}_{7} \mathrm{O}_{24}\right]^{6-}$ does not induce electron transfer across the Mo-O bond and consequently this complex is stable and can be isolated. It is well known that the hard $\mathrm{O}^{2-}$ ligand can stabilize (coexist with) higher oxidation states of metal. Thus the structural aspects of Mo-S complexes indicate that the all-sulphur analogue of heptamolybdate with several Mo$\mathrm{S}$ (term) bonds at shorter distances than in $\left[\mathrm{MoS}_{4}\right]^{2-}$ is not stable and is prone to internal redox reactions. In the absence of theoretical evidence to further support this fact, it will be premature to label the $\left[\mathrm{Mo}_{7} \mathrm{~S}_{24}\right]^{6-}$ complex as a non-existent complex. However, based on the present results it can be stated that this complex cannot exist in an alkaline medium and also cannot be isolated from an aqueous acidic medium.

\section{Conclusions}

Dianionic $\left[\mathrm{MoX}_{4}\right]^{2-}(\mathrm{X}=\mathrm{O}$ or $\mathrm{S})$ complexes exist as the monomeric tetrahedral species in aqueous alkaline solutions. Reaction of an ammoniacal molyb- date solution with $\mathrm{H}_{2} \mathrm{~S}$ results in the formation of $\left(\mathrm{NH}_{4}\right)_{2}\left[\mathrm{MoS}_{4}\right]$ 1. Passing $\mathrm{H}_{2} \mathrm{~S}$ gas for extended periods does not result in the formation of any polynuclear Mo-S complex other than $\left[\mathrm{MoS}_{4}\right]^{2-}$. All attempts to prepare $\mathbf{2}$ by acidification (with excess acid) of $\left(\mathrm{NH}_{4}\right)_{2}\left[\mathrm{MoS}_{4}\right] \mathbf{1}$ results in the formation of the insoluble $\mathrm{MoS}_{3}$. The first product of acidification of $\left[\mathrm{MoS}_{4}\right]^{2-}$ is the dinuclear complex $\left[\mathrm{Mo}_{2} \mathrm{OS}_{7}\right]^{2-}$. The same complex can also be prepared by directly passing $\mathrm{H}_{2} \mathrm{~S}$ into an aqueous ammonium heptamolybdate solution $(\mathrm{pH}=5 \cdot 5)$ indicating the difference in the nature of the Mo-S product formed, depending upon the medium $\mathrm{pH}$. Formation of the reduced dinuclear $\mathrm{Mo}(\mathrm{V})$ complex instead of the all-sulphur analogue of heptamolybdate is explained based on bond distances or closer approach of S to Mo. Formation of the dinuclear $\mathrm{Mo}(\mathrm{V})$ complex precludes the formation of any higher nuclearity Mo-S complexes in aqueous solution. The all-sulphur analogue of heptamolybdate 2 cannot exist in an alkaline medium and also cannot be isolated from an aqueous acidic medium.

\section{Acknowledgements}

The author acknowledges his deep sense of gratitude to Prof S Sankar, Indian Institute of Technology, 
Kanpur for introducing him to the fascinating chemistry of Mo-S compounds. He thanks Mr S N Dhuri and $\mathrm{Mr}$ A R Naik for the $\mathrm{pH}$ measurements, Dr K S Rane for helpful discussions and the University Grants Commission, New Delhi for financial support.

\section{References}

1. Cotton F A, Wilkinson G, Murillo C A and Bochmann M 1999 Advanced inorganic chemistry 6th edn (New York: John Wiley and Sons) pp 920-934

2. Müller A, Peters F, Pope M T and Gatteschi D 1998 Chem. Rev. 98239

3. Müller A., Krickemeyer E, Meyer J, Bögge H, Peters F, Plass W, Diemann E, Dillinger S, Nonnenbruch F, Renderath M and Menke C 1995 Angew. Chem., Int. Ed. Engl. 342121

4. Müller A., Krickemeyer E, Bögge H, Schmidtmann M, Peters F, Beugholt C, Kögerler P and Lu C 1998 Angew. Chem., Int. Ed. Engl. 371220

5. Müller A., Krickemeyer E, Bögge H, Schmidtmann M, Peters F, Menke C and Meyer J 1997 Angew. Chem., Int. Ed. Engl. 36484

6. Müller A, Krickemeyer E, Bögge H, Schmidtmann M and Peters F 1998 Angew. Chem., Int. Ed. Engl. 37 3360

7. Müller A, Sarkar S, Shah S Q N, Bögge H, Schmidtmann M, Sarkar S, Kögerler P, Hauptfleisch B, Trautwein A X and Schunemann V 1999 Angew. Chem., Int. Ed. Engl. 383238

8. Müller A, Polarz S, Das S K, Krickemeyer E, Bögge H, Schmidtmann M and Hauptfleisch B 1999 Angew. Chem., Int. Ed. Engl. 383241

9. Cruywagen J J, Esterhuysen M W and Heyns J B B 2003 Inorg. Chim. Acta 348205

10. Chakrabarti S and Natarajan S 2002 Crystal Growth Design 2333

11. Boschen I P 1979 Chem. Commun. 780

12. Shivaiah V, Reddy P V N, Cronin L and Das S K 2002 J. Chem. Soc., Dalton Trans. 3781

13. The $\mathrm{pH}$ of a $5 \%$ aqueous solution of heptamolybdate is 5.0 to 5.5. 1976 Merck Index 9th edn Merck \& Co. Inc, Rathaway, NJ, pp 73-74

14. Cruywagen J J, Draaijer A G, Heyns J B B and Rohwer 2002 Inorg. Chim. Acta 331322

15. Evans H T Jr 1968 J. Am. Chem. Soc. 903275

16. Gatehouse B M and Leverett P 1968 Chem. Commun. 901

17. Sjöbom K and Hedman B 1973 Acta Chem. Scand. A27 3673

18. Don A and Weakly T J R 1981 Acta Crystallogr B37 451

19. Ohashi Y, Yanagi K, Sasadi Y and Yamase T 1982 Bull. Chem. Soc. Jpn. 551254

20. Roman P, Gutierrez-Zorrila J M, Luque A and Martinez-Ripoll M 1998 J. Crystallogr. Spectrosc. Res. 18 107

21. Roman P, Luque A, Aranzabe A and GutierrezZorrila J M 1992 Polyhedron 112027
22. Himeno S, Niija H and Ueda T 1997 Bull. Chem. Soc. Jpn. 70631

23. Greenwood N N and Earnshaw A 1984 Chemistry of the elements (London: Pergamon) pp 1171-1183

24. Bensch W, Hug P, Emmenegger R, Reller A and Oswald H R 1987 Mater. Res. Bull. 22447

25. MacDonald J W, Friesen G D, Rosenhein L D and Newton W E 1983 Inorg. Chim. Acta 72205

26. Berzelius J J 1826 Poggendorffs Ann. Phys. Chem. 7 262

27. Coucouvanis D 1998 Adv. Inorg. Chem. 451

28. Müller A, Diemann E, Jostes R and Bögge H 1981 Angew. Chem., Int. Ed. Engl. 20934

29. Müller A and Sarkar S 1977 Angew. Chem., Int. Ed. Engl. 16705

30. Sarkar S and Mishra S B S 1985 J. Indian Chem. Soc. 62821

31. Sarkar S and Mishra S B S 1987 Indian J. Chem. A25 871

32. Srinivasan B R and Sarkar S 1990 Inorg. Chem. 29 3898

33. Wang H W, Skeldon P, Thompson G E and Wood G C 1997 J. Mater. Sci. 32497

34. Nath M, Govindaraj H and Rao C N R $2001 A d v$. Mater. 13283

35. Ilankumaran $\mathrm{P}$, Prabhu $\mathrm{K} \mathrm{R}$ and Chandrasekaran $\mathrm{S}$ 1997 Synth. Commun. 27 4031; Devan N, Sureshkumar D, Beadham I, Prabhu K R and Chandrasekaran S 2002 Indian J. Chem. B41 2112

36. Ramesha A R and Chandrasekaran S 1992 Synth. Commun. 223277

37. Prabhu K R, Devan N and Chandrasekaran S 2002 Synlett. 1762, and references cited therein

38. Svehla G 1982 Vogel's textbook of macro and semimicro qualitative inorganic analysis 5 th edn (New Delhi: Orient Longman) pp 512-513

39. Xin X, Morris N L, Jameson G B and Pope M T 1985 Inorg. Chem. 243482

40. Xu J Q, Zhou X H, Zhou L M, Wang T G, Huang X $\mathrm{Y}$ and Averill B A 1999 Inorg. Chim. Acta 285152

41. Pan W H, Harmer M A, Halbert T R and Stiefel E I 1984 J. Am. Chem. Soc. 106459

42. Chandrasekaran J, Ansari M A and Sarkar S 1987 J. Less Common Metals 134123

43. McConnachie C A and Stiefel E I 1999 Inorg. Chem. 38964

44. Polshettiwar V, Nivsarkar M, Acharya J and Kaushik M P 2003 Tetrahedron Lett. 44887

45. Srinivasan B R, Dhuri S N and Naik A R 2004 Tetrahedron Lett. 452247

46. State H M 1950 Inorg. Syn. 6200

47. Bassett J, Denney R C, Jeffery G H and Mendham J 1978 Vogel's textbook of quantitative inorganic analysis 4th edn (London: ELBS).

48. Ellermeier J, Näther C and Bensch W 1999 Acta Crystallogr. C55 501

49. Srinivasan B R and Dhuri S N, unpublished results

50. Srinivasan B R, Vernekar B K and Nagarajan K 2001 Indian J. Chem. A39 563

51. Srinivasan B R, Dhuri S N, Poisot M, Näther C and Bensch W 2004 Z. Naturforschung. B (in press); 
Srinivasan B R, Dhuri S N, Näther C and Bensch W 2004 Inorg. Chim. Acta (in press)

52. Pokhrel S, Nagaraja K S and Varghese B $2003 \mathrm{~J}$. Chem. Crystallogr. 33903

53. Pokhrel S, Nagaraja K S and Varghese B $2003 \mathrm{~J}$. Struc. Chem. 44689

54. Müller A, Sarkar S, Bhattacharyya R G, Pohl S and Dartmann M 1978 Angew. Chem., Int. Ed. Engl. 17 534

55. Chandrasekaran J, Ansari M A and Sarkar S 1988 Inorg. Chem. 273663

56. Lyxell D G, Pettersson L and Persson I 2001 Inorg. Chem. $\mathbf{4 0} 584$
57. Lapasset P J, Chezeau N and Belougne P 1973 Acta Crystallogr. B32 3087

58. Clegg W, Christou G, Garner C D and Sheldrick G M 1981 Inorg. Chem. 201562

59. Draganjac M, Simhon E, Chan L T, Kanatzidis M, Baenziger N C and Coucouvanis D 1982 Inorg. Chem. 213321

60. Bunzey G and Enemark J H 1978 Inorg. Chem. 17682

61. Huneke J T and Enemark J H 1978 Inorg. Chem. 17 3698

62. Coucouvanis D, Draganjac M E, Koo S M, Toupadakis A and Hadjikyriacou 1992 Inorg. Chem. 31 1186 